\title{
Adsorption of Tartrazine onto Activated Carbon Based Cola Nuts Shells: Equilibrium, Kinetics, and Thermodynamics Studies
}

\author{
Dantio Nguela Christian Brice, Ngomo Horace Manga, Bénédoué Serge Arnold, Kouotou Daouda, \\ Abega Aimé Victoire, Ndongo Ndongo Alain Giresse, Che Randy Nangah, Ndi Julius Nsami*
}

Laboratory of Applied Physical and Analytical Chemistry, Department of Inorganic Chemistry, Faculty of Science, University of Yaoundé I, Yaoundé, Cameroon

Email: ^bigpielo2002@yahoo.com

How to cite this paper: Brice, D.N.C., Manga, N.H., Arnold, B.S., Daouda, K., Victoire, A.A., Giresse, N.N.A., Nangah, C.R. and Nsami, N.J. (2021) Adsorption of Tartrazine onto Activated Carbon Based Cola Nuts Shells: Equilibrium, Kinetics, and Thermodynamics Studies. Open Journal of Inorganic Chemistry, 11, 1-19. https://doi.org/10.4236/ojic.2021.111001

Received: August 7, 2020

Accepted: January 22, 2021

Published: January 25, 2021

Copyright $\odot 2021$ by author(s) and Scientific Research Publishing Inc. This work is licensed under the Creative Commons Attribution International License (CC BY 4.0).

http://creativecommons.org/licenses/by/4.0/

(c) (i) Open Access

\begin{abstract}
The uptake of tartrazine from its aqueous solution by powdered activated carbon prepared from cola nut shells chemically activated with potassium hydroxide (ACK) and phosphoric acid (ACP) has been investigated using kinetics models. Batch isotherm data were analysed with the pseudo-first order, pseudo-second order model as well as the intraparticle diffusion model. For structural elucidation, the materials were characterized using FTIR, XRD and SEM. These analyses revealed that the activated carbons (ACK and ACP) were predominantly mesoporous with several oxygen-containing functional groups dispersed on their surface. The reaction was systematically investigated under various experimental conditions such as contact time, adsorbent dose and $\mathrm{pH}$. For the two adsorbents, the quantity adsorbed of $19.256 \mathrm{mg} / \mathrm{g}$ and $18.196 \mathrm{mg} / \mathrm{g}$ respectively for ACP and ACK at respective contact times of 5 and 10 min were obtained. The adsorption data were tested with the Langmuir, Freundlich models. Langmuir model was found to best describe the adsorption of tartrate ions with maximum monolayer adsorption capacities of 24.57 and $21.59 \mathrm{mg} / \mathrm{g}$ for ACP and ACK, respectively. Results analysis indicated clearly that the pseudo-second order kinetic rate model best fitted the experimental data and therefore was the adsorption controlling mechanism for both adsorbents. Thermodynamic studies revealed that the adsorption process was spontaneous and exothermic for ACP with increased randomness at the solid solution interface, then exothermic but non-spontaneous for ACK. The results show that these activated carbons could be an alternative for more costly adsorbents for the purpose of tartrate ions elimination.
\end{abstract}




\section{Keywords}

Cola Nuts Shells, Activated Carbon, Adsorption, Tartrazine

\section{Introduction}

Though industrial activities have contributed to the development of many countries, they have also generated undesirable by-products, which constitute the main part of the discharged effluents. These industrial effluents are organic (dyes, pesticides) and inorganic (heavy metals) pollutants. Owing to their appearance, coloured organic compounds are easily recognizable pollutants. These chemical pollutants in industrial effluents are mostly non-biodegradable and highly toxic as they affect aquatic ecosystems, destroy wildlife and affect human health, provoking conditions such as rashes, allergic reactions, dysfunction of the kidney, the reproductive system and the central nervous system in humans [1] [2].

Dye under investigation, tartrazine (otherwise known as E102 or FD \& C Yellow 5), is a lemon yellow azo dye manufactured from coal-tar derivative and used as a food colouring. It is found in certain brands of fruit squash, fruit cordial, coloured fizzy drinks, instant puddings, cake mixes, custard powder, soups, sauces, ice cream, ice lollies, sweets, chewing gum, marzipan, jam, jelly, marmalade, mustard, yoghurt and many convenience foods [3]. It is cheaper than beta-carotene and therefore used as an alternative to beta-carotene to achieve similar colour [4]. Water-soluble tartrazine is used in drugs, especially shells of medicinal capsules, syrups and cosmetics. The wide use of tartrazine in industry and its water-soluble nature maximize its chances to be found as contaminant in industrial effluents [5]. Tartrazine is also reputed to catalyse hyperactivity [6]. and other behavioural problems [7], asthma [8] [9], migraines, thyroid cancer [10]. According to $\mathrm{WHO}$, the acceptable daily intake (ADI) of tartrazine is 7.5 $\mathrm{mg} / \mathrm{kg}$ of body mass, which classifies it as a very toxic substance. It is therefore important to treat wastewaters containing tartrazine before their injection into the environment.

Many methods including chemical precipitation, filtration, ion exchange, reverse osmosis, ultra-filtration, biological degradation, membrane separation, solvent extraction and adsorption have been employed to remove pollutants. Adsorption remains the most utilised process because of its simplicity, high efficiency and easy recovery [11]. In the scientific literature, typical adsorbents include zeolite, clay, silica gel, resins, activated alumina and activated carbon [12] [13]. Activated carbon (AC) is the most widely used owing to its well-developed pore structure, large active surface area, good mechanical properties and multiple functional groups at their surface [14] [15]. There are many precursors from which AC can be prepared some of these include corn cobs [2], apricot stone [16], sugarcane bagasse, coconut shells [17], peanut hull [18], rattan bam- 
boo, sawdust [19], hazelnut bagasse [20], cotton stalk fibre [1], rice husk [21], cola nut shell [11], and olive stone [22].

The goal of the present study, is to evaluate the adsorption capacities of activated carbon prepared from cola nut shells activated separately with $\mathrm{KOH}$ and $\mathrm{H}_{3} \mathrm{PO}_{4}$ to remove tartrazine from aqueous solution using batch system and to get an insight into the adsorption controlling mechanism by testing the experimental data with well-known linear and nonlinear kinetic models applied to liquid phase adsorption.

\section{Experimental Methods}

\subsection{Preparation of Absorbents}

The procedure for the preparation of the activated carbon (AC) used in this work has-been reported by [23]. The raw material constituted by kola nut shell was collected in the region of the Northwest Cameroon, more exactly in the department of Donga-Mantum; these cola nut shells are classified in the group of lignocellulosic compounds. These shells contain essentially organic, mineral substances and water, thus constitute a real source of agricultural waste, possessing interesting physico-chemical characteristics for the production of activated charcoals.

The kola nut shells collected are abundantly washed in the current water to eliminate the impurities, rinsed in the distilled water and then dried in air during two weeks. Once dried, they are crushed until the obtaining of fragments having a size between 1.25 and $2.5 \mathrm{~mm}$. These fragments are impregnated with the potassium hydroxide $(\mathrm{KOH})$ and the phosphoric acid $\left(\mathrm{H}_{3} \mathrm{PO}_{4}\right)$ with a ratio of 1:1 (mass activing agent/mass of raw material).

After impregnation, these fragments of cola nut shells were dried in the oven room at $110^{\circ} \mathrm{C}$ during 24 hours. The carbonization of material was made at $500^{\circ} \mathrm{C}$ during 1 hour and cool down until the room temperature.

After cooling, the activated carbon was washed with distilled water until neutral $\mathrm{pH}$ was obtained, then crushed in a mortar by means of a pestle, until the obtaining of the powder.

\subsubsection{Characterization of Activated Carbons}

Samples of activated carbon were characterised using various techniques: Infrared spectroscopy (IR) to probe the surface functional group, Scanning Electron Microscopy (SEM) to investigate the surface morphology, X-ray diffraction (XRD) analysis was to evaluate the crystalline or amorphous structure and the BET method to determine the specific surface area. The iodine number was determined to evaluate the microporosity.

\subsubsection{Preparation of Adsorbate}

The tartrazine stock solution $(60 \mathrm{ppm})$ was prepared by dissolving $0.015 \mathrm{~g}$ of tartrazine powder with distilled water in a $250 \mathrm{~mL}$ volumetric flask. The solution was stirred for 24 hours to obtain the homogeneity. From this solution, dilute 
solutions of $1,3,5,7,9,11,13$ and $15 \mathrm{mg} / \mathrm{L}$ were prepared. $0.1 \mathrm{M}$ hydrochloric acid and $0.1 \mathrm{M}$ sodium hydroxide were also prepared for $\mathrm{pH}$ adjustments, by dilution of initial hydrochloric acid of $37 \%$ and $2 \mathrm{~g}$ of sodium hydroxide in conical flasks.

\subsection{Batch Adsorption Experiments}

Batch adsorption isotherm study was carried out through several experimental runs. For each run, $20 \mathrm{ml}$ of tartrazine dye of known initial concentration was added to a known mass of adsorbent and agitated for a predetermined time. After agitation, the solution was filtered using which wattman $\mathrm{N}^{\circ} 4$ filtered paper and the concentration of the supernatant fluid measured using a TECHMEL-TECHMEL S-23A UV-visible spectrophotometer at the wave length of $420 \mathrm{~nm}$. Similar measurements were carried out with varying adsorbent doses, solution $\mathrm{pH}$ and initial concentrations of tartrazine.

The quantity adsorbed $\left(Q_{e}\right)$ adsorbed per unit mass of adsorbent, and the percentage removal (\% R) were calculated using the following equations:

$$
\begin{gathered}
Q_{e}=\frac{\left(C_{0}-C_{e}\right) V}{m} \\
R=\frac{\left(C_{0}-C_{e}\right) 100}{C_{0}}
\end{gathered}
$$

where $C_{0}$ is the initial concentration, $C_{e}$ the equilibrium concentration, $V$ the volume and $\mathrm{m}$ is the mass of the adsorbent.

\section{Results and Discussion}

\subsection{On the Characterization of Adsorbent}

\subsubsection{Powder X-Ray Diffraction Analysis}

The XRD spectrum of AC recorded between 5 to 70 degrees is presented in Figure 1 . The region between 7 and 70 degrees indicates the absence of any crystalline structure with the absence of any well-defined peak, which is an indication of an amorphous structure

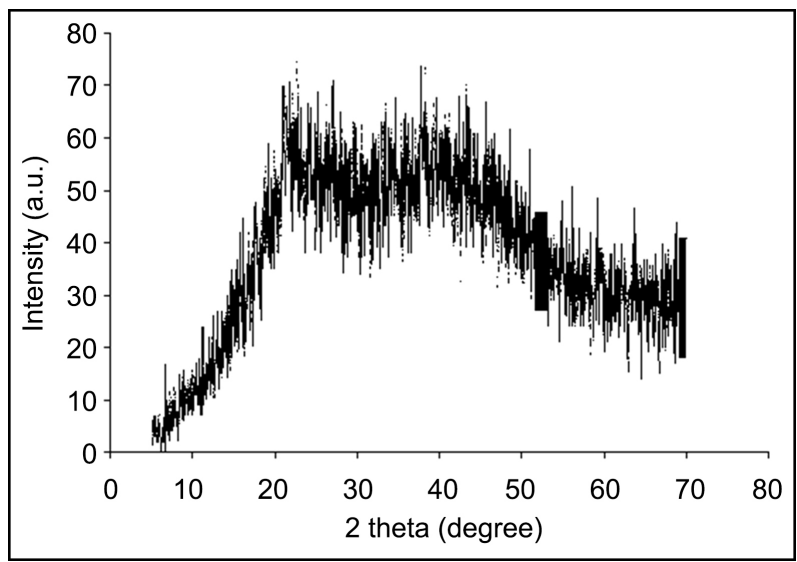

Figure 1. X-ray diffractogram of AC. 
This result is in good agreement with the nature of activated carbon prepared by others researchers reported in literature.

\subsubsection{Infrared Spectroscopy Analysis of ACK and ACP}

The FT-IR spectroscopy analysis allows identifying functional groups present on the adsorbents surface. Figure 2 and Figure 3 below shows the FT-IR spectra of both AC before adsorption:

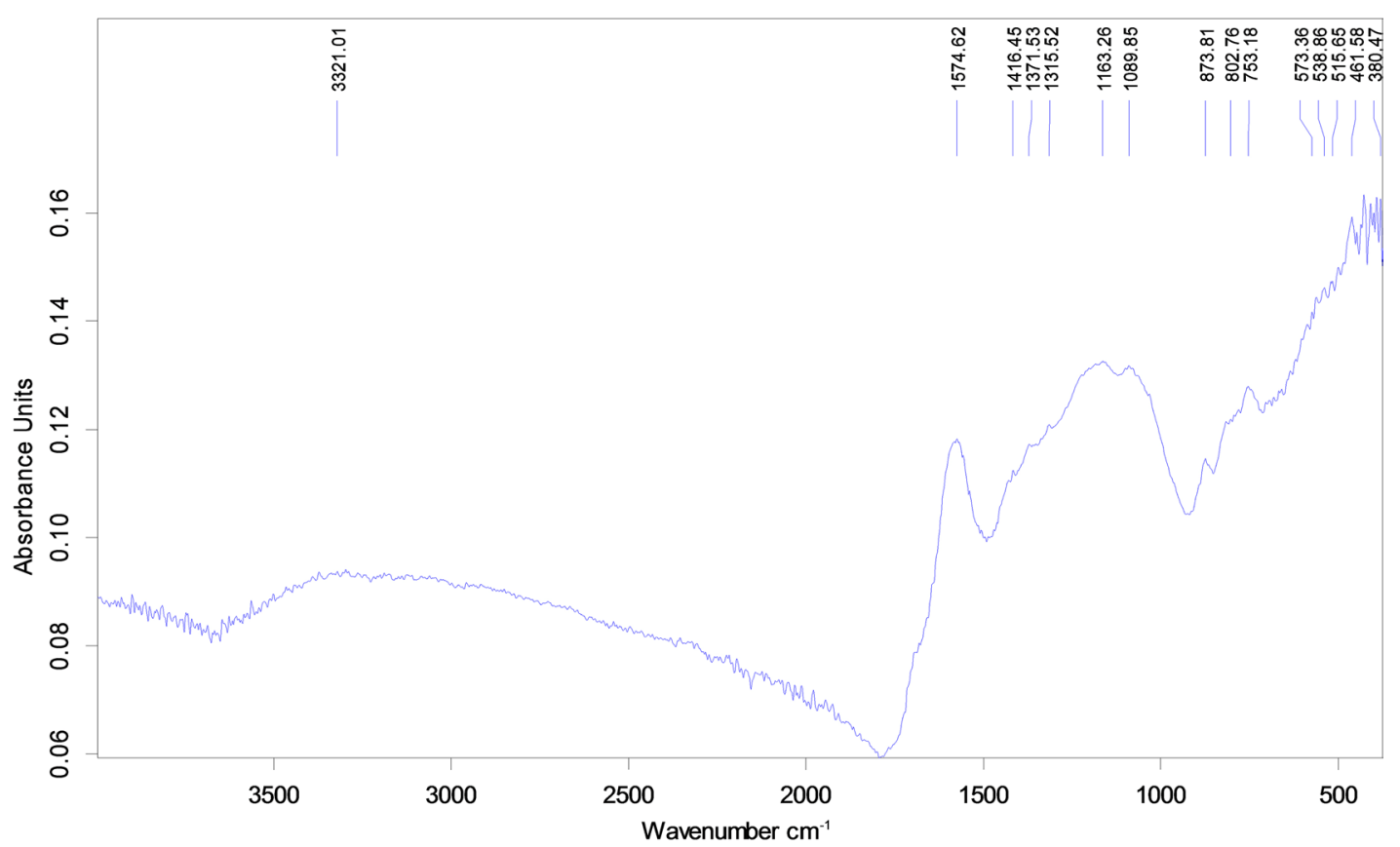

Figure 2. Infrared spectrum of ACK before adsorption.

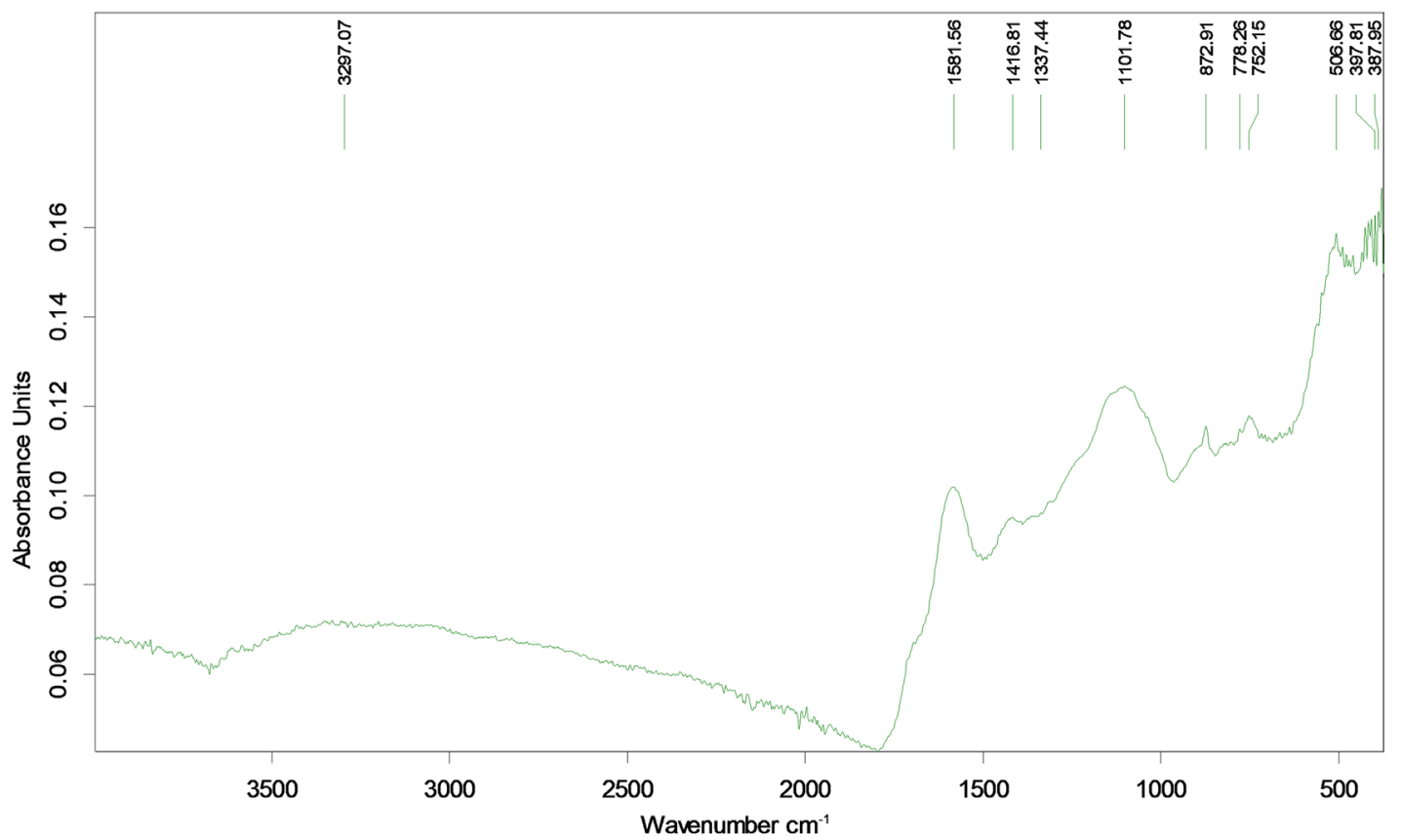

Figure 3. Infrared spectrum of ACP before adsorption. 
On the recorded spectra, there are bands at $3321 \mathrm{~cm}^{-1}$ and $1574 \mathrm{~cm}^{-1}$ corresponding to $\mathrm{O}-\mathrm{H}$ and $\mathrm{C}=\mathrm{C}$ stretching vibration of phenolic and aromatic rings, respectively. The bands at 1416 and $1371 \mathrm{~cm}^{-1}$ are attributed to the $\mathrm{N}-\mathrm{H}$ of amines and $\mathrm{C}-\mathrm{H}$ of benzene bending vibration of respectively; the band at 1163 $\mathrm{cm}^{-1}$ cis attributed to $\mathrm{C}-\mathrm{O}$ stretching vibration, whereas the bands at 873,802 and $753 \mathrm{~cm}^{-1}$ correspond to the $\mathrm{C}-\mathrm{H}$ stretching vibration of benzene para, meta and ortho-substituted, respectively. The frequencies at of 573,538 and $515 \mathrm{~cm}^{-1}$ are attributed to the $\mathrm{O}-\mathrm{K}$ stretching vibration coming from the $\mathrm{AC}$ activation by $\mathrm{KOH}$.

On the ACP spectra the bands which appear at 3297 and $1581 \mathrm{~cm}^{-1}$ are attributed to $\mathrm{O}-\mathrm{H}$ and $\mathrm{C}=\mathrm{C}$ stretching vibration of phenolic and aromatic rings, respectively. The bands at 1416 and $1337 \mathrm{~cm}^{-1}$ correspond to $\mathrm{N}-\mathrm{H}$ of amines and $\mathrm{C}-\mathrm{H}$ of benzene bending vibration respectively. The band at $1101 \mathrm{~cm}^{-1}$ is attributed to C-O stretching vibration, whereas the bands at 872,778 and $753 \mathrm{~cm}^{-1}$ correspond to the $\mathrm{C}-\mathrm{H}$ stretching vibration of benzene para, meta and ortho-substituted, respectively. The frequencies at of 506, 397 and $387 \mathrm{~cm}^{-1}$ are due to the O-P stretching vibration coming from the $\mathrm{AC}$ activation by $\mathrm{H}_{3} \mathrm{PO}_{4}$ [24].

\subsubsection{SEM Microstructural Analysis of ACP and ACK}

To view the effect of activation on the pore structure of the precursor, SEM micrographs of the precursor before activation and after activation (ACP and $\mathrm{ACK}$ ) were carried out. Figure 4 illustrates the micrograph of the precursor before activation.

It is observed that the pores on the surface of the precursor are less developed. This poor pore distribution on its surface makes the precursor an unlikely candidate as an adsorbent. Nevertheless, activation could result to the presence surface functional groups which favoured ion exchange and increased porosity. Figure 5 in turn displays the surfaces of the activated carbons ACP and ACK.

Compared to the micrograph of the precursor (Figure 4), the micrographs of ACP and ACK show a highly developed porosity over the entire sample surface resulting from the effect of chemical activation by phosphoric acid and potassium hydroxide. The pores are heterogeneous and not evenly distributed. It can also be seen that the pores of ACK are larger than those of ACP, but ACP has a more developed distribution of pores. This could explain the higher surface area for ACP than ACK (as seen in the BET results below).

\subsubsection{Textural Properties of ACP and ACK}

The textural properties of ACP and ACK were determined by the BET nitrogen adsorption-desorption, $\mathrm{BJH}$ analysis and the iodine number. These parameters are shown in Table 1.

The pore diameter of ACP and ACK is between 2 and $50 \mathrm{~nm}$, indicating that both materials are mesoporous. Interestingly, the mean pore size of ACK is bigger than that of ACP in good agreement with SEM analysis. The value of the iodine number $(513.945 \mathrm{mg} / \mathrm{g}$ ) for ACK is within the 500 and $1200 \mathrm{mg} / \mathrm{g}$ range and indicates the presence of micropores. 


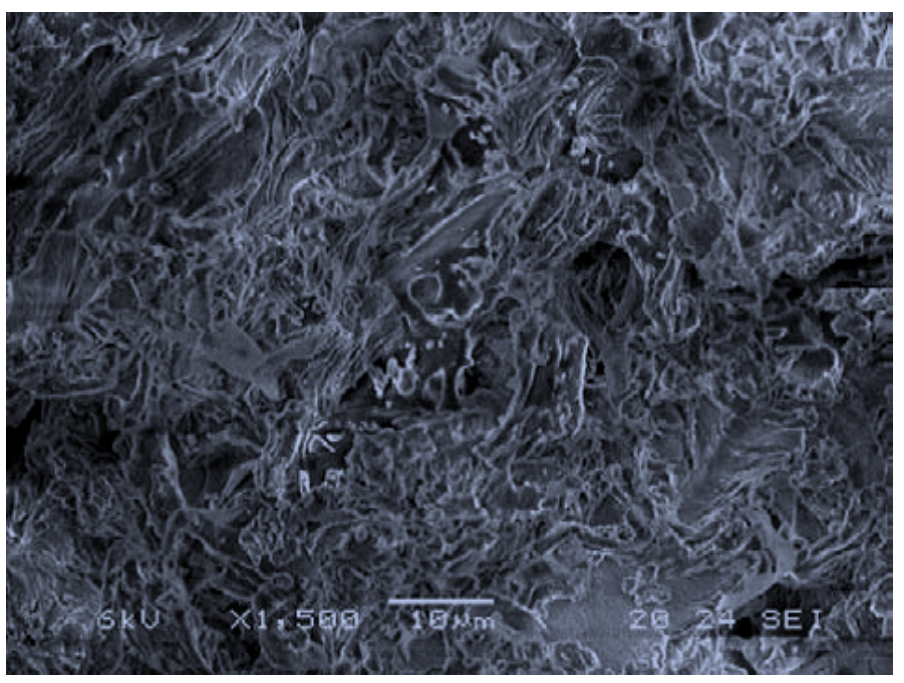

Figure 4. Scanning electron micrograph of cola nutshells [23].

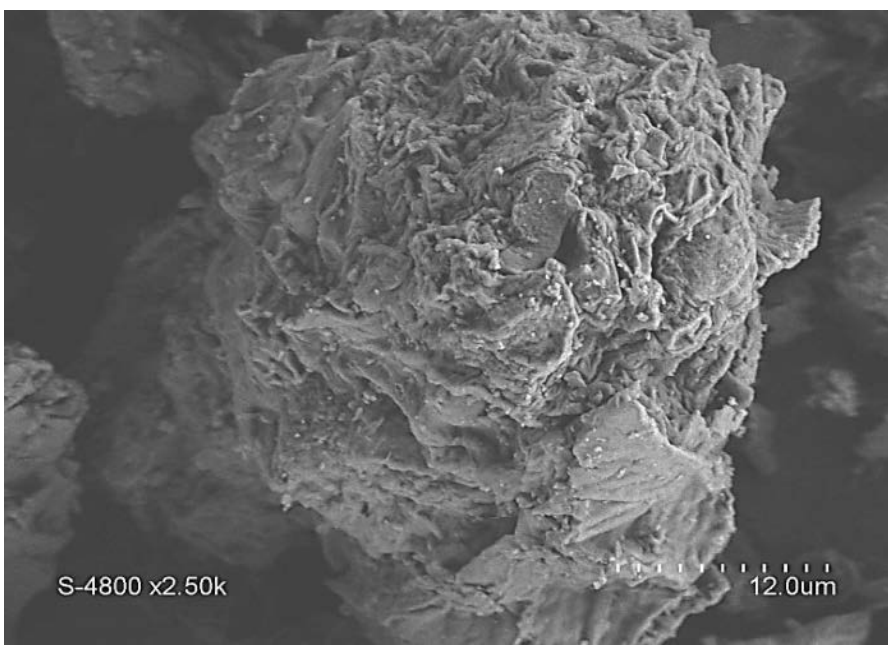

(a)

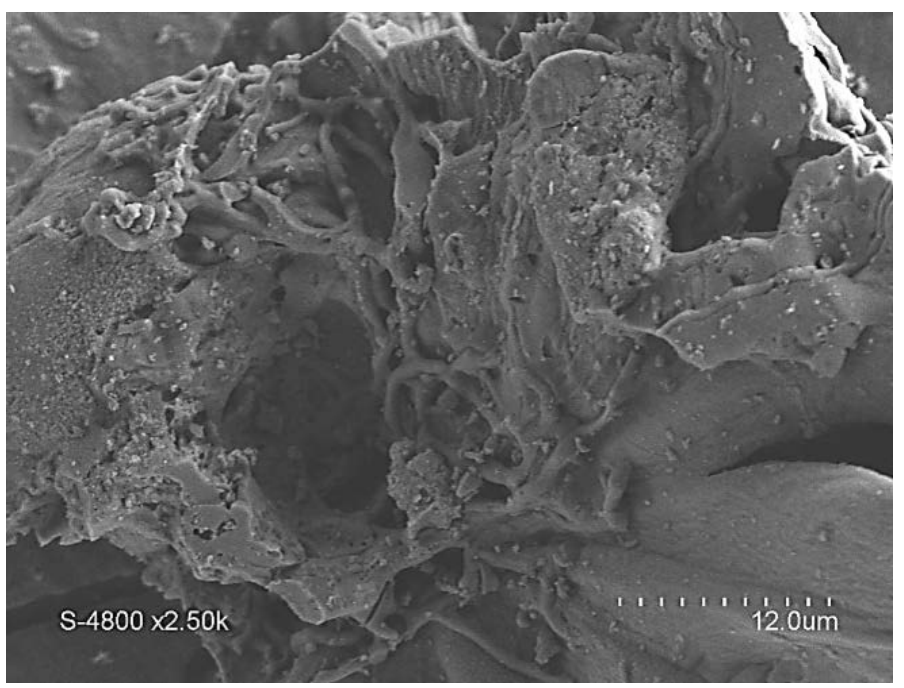

(b)

Figure 5. SEM Micrographs of ACP (a) and the ACK (b) [23]. 
Table 1. Textural properties of the ACP and ACK [23].

\begin{tabular}{ccc}
\hline Analysis & ACP & ACK \\
\hline BET specific surface area $\left(\mathrm{m}^{2} / \mathrm{g}\right)$ & 6.276 & 2.045 \\
Pore adsorption cumulative surface $\mathrm{area}\left(\mathrm{m}^{2} / \mathrm{g}\right)$ & 3.255 & 0.992 \\
Pore desorption cumulative surface $\mathrm{area}\left(\mathrm{m}^{2} / \mathrm{g}\right)$ & 0.992 & 2.672 \\
Total pore volume $\left(\mathrm{cm}^{3} / \mathrm{g}\right)$ & 0.009 & 0.005 \\
Average pore diameter $(\AA)$ & 61.000 & 94.000 \\
Iodine Number $(\mathrm{mg} / \mathrm{g})$ & 441.612 & 513.945 \\
\hline
\end{tabular}

\subsection{Adsorption}

All adsorption experiments were carried out at $\mathrm{pH} 2$ because at $\mathrm{pH}$ greater than or less than 2, the adsorbed quantities were near to zero. The same results was obtained by Sushmita Banerjee [25] during the Adsorption characteristics for the removal of a toxic dye, tartrazine from aqueous solutions by a low cost agricultural by-product. They found that tartrazine was better adsorbed under acid medium.

\subsubsection{Influence of Contact Time}

Figure 6 exhibits the effect of contact time on the adsorption of tartrazine and the experiments were tested by carrying out experimental runs from 5 to $70 \mathrm{~min}$ for ACP and ACK, at an initial tartrazine concentration of $20 \mathrm{mg} / \mathrm{L}$, and with a mass of $0.01 \mathrm{~g}$ of ACP and ACK.

The adsorption of tartrazine is seen to rise steadily from 0 to 5 minutes with adsorbed quantities of $19.42 \mathrm{mg} / \mathrm{L}$ for ACP and $17.84 \mathrm{mg} / \mathrm{L}$ for ACK. This initial spurt may be due to the availability of adsorption sites on the surface of adsorbent materials [16]. After this time, the system is seen to attain equilibrium with the saturation of the active sites of both absorbents. This equilibrium is attained after 5 mins for ACP and 10 mins for ACK.

\subsubsection{Influence of the Mass of Adsorbent}

Figure 7 below displays the influence of the adsorbent mass varying from $0.01 \mathrm{~g}$ to $0.06 \mathrm{~g}$, at a contact time of $5 \mathrm{~min}$ for ACP and 10 mins for ACK and adsorbate dose of $20 \mathrm{mg} / \mathrm{L}$.

From Figure 7, the amount adsorbed at equilibrium decreases as the mass of both adsorbents (ACK and ACP) is increased. At higher adsorbent mass, agglomeration of the adsorbent particles occurs due to electrostatic attractive forces between the AC particles. This impedes access to adsorption sites, hence the decrease in adsorbed quantity. This may be also due to the fact that as the amount of the adsorbent increases, the total surface area available for the adsorption of tartrazine molecules reduces as a result of the overlapping or aggregation of adsorption sites [26]. Similar results were obtained by [27] in the study of the adsorption of zinc ions on rice balls [17]. Maximum adsorption was thus recorded at a mass of $0.01 \mathrm{~g}$. 


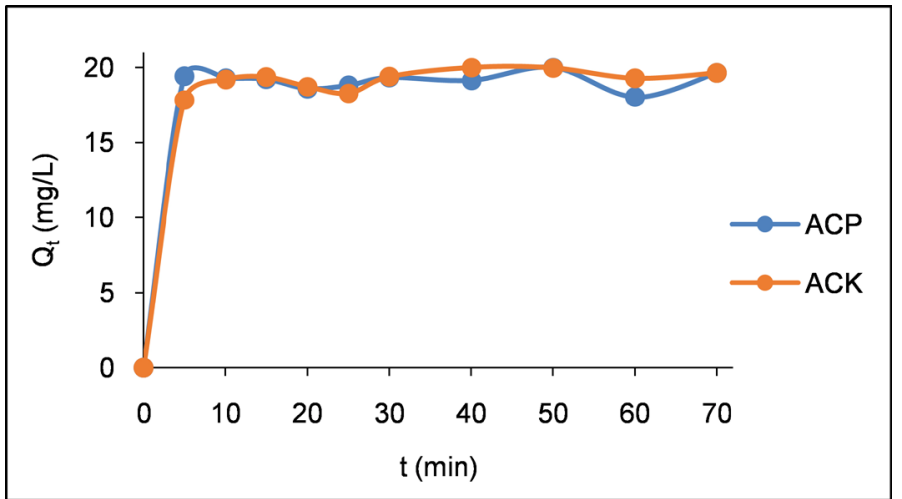

Figure 6. Influence of contact time on the adsorption of tartrazine by ACP and ACK.

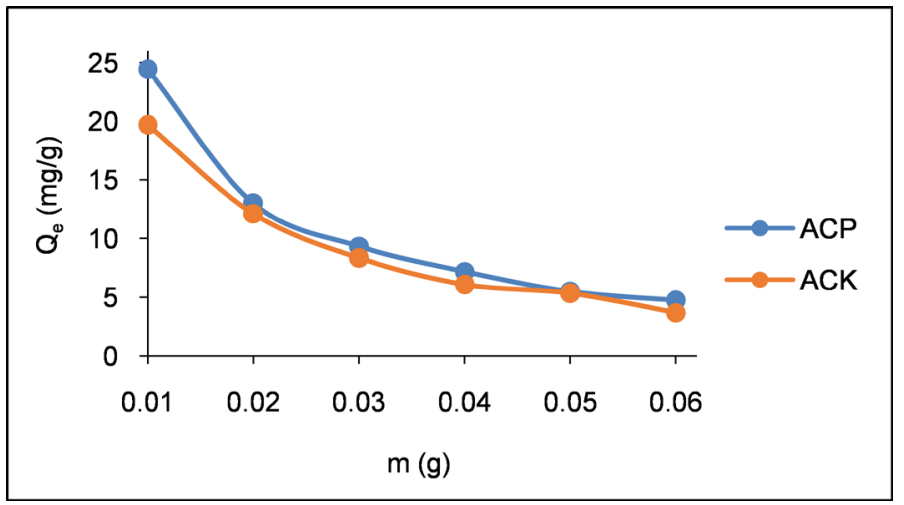

Figure 7. Influence of the mass of adsorbent on the quantity adsorbed.

\subsubsection{Influence of Initial Concentration}

The initial concentration of the adsorbate was varied between 5 and $30 \mathrm{mg} / \mathrm{L}$. As seen from Figure 8, the quantity of tartrazine adsorbed increases from 6.01 to $18.04 \mathrm{mg} / \mathrm{g}$ and from 6.4 to $18.19 \mathrm{mg} / \mathrm{g}$ respectively for ACP and ACK as the initial concentration rises from 5 to $25 \mathrm{mg} / \mathrm{L}$. This observed increase results from a higher collision rate between tartrazine molecules and the adsorbent surface as the concentration of tartrazine increases [18]. This trend is observed for both adsorbents until an adsorbate concentration of $25 \mathrm{mg} / \mathrm{L}$, beyond which it starts decreasing for ACK. This indicates that at higher concentrations, tartrazine molecules accumulate on the surface of ACK and block the pore openings [19], observed a similar trend for the adsorption of methylene blue on bamboo-based activated carbon.

From the batch adsorption studies, we note that the quantities adsorbed by the ACP and ACK are almost the same although ACP has a surface area almost three times higher than that of ACK. ACK however, has a higher mean pore diameter and a more pronounced surface heterogeneity than ACP due to the presence of both meso and micropores on its surface, which promote good adsorption. This parameter could therefore justify the near identical adsorbed quantities. 
We also carried out FTIR analysis on the adsorbents after adsorption. The results are represented in Figure 9 and Figure 10. Here we note the disappearance of the $-\mathrm{OH}$ stretching vibration at $3321.01 \mathrm{~cm}^{-1}$ after adsorption on the spectrum of ACK (Figure 9); this disappearance could be as a result of the reaction between the acid group on adsorbents surface and sulphonates functional group of the tartrazine with the release of a water molecule.

\subsection{Adsorption Isotherms}

The equilibrium data was analysed using the using the following linearized isotherm models as given in Equations (3)-(5).

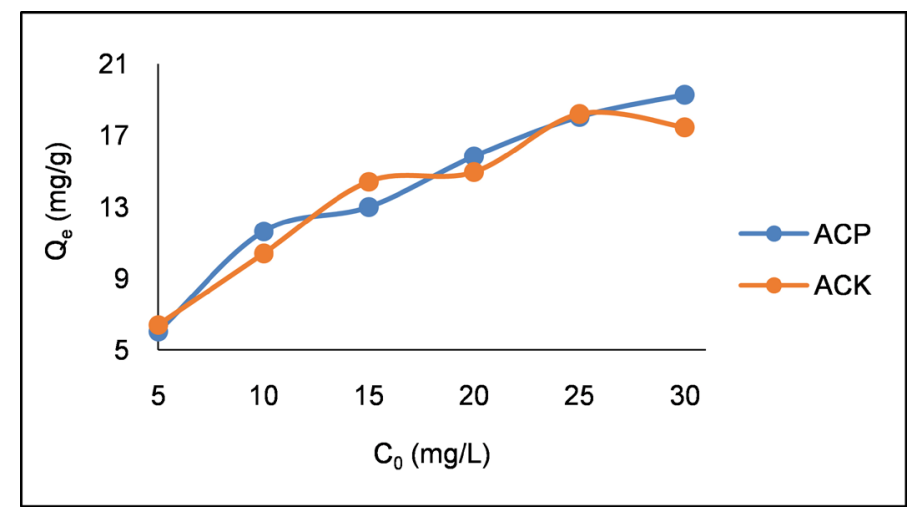

Figure 8. Influence of the initial concentration on the amount of tartrazine adsorbed by ACK and ACP.

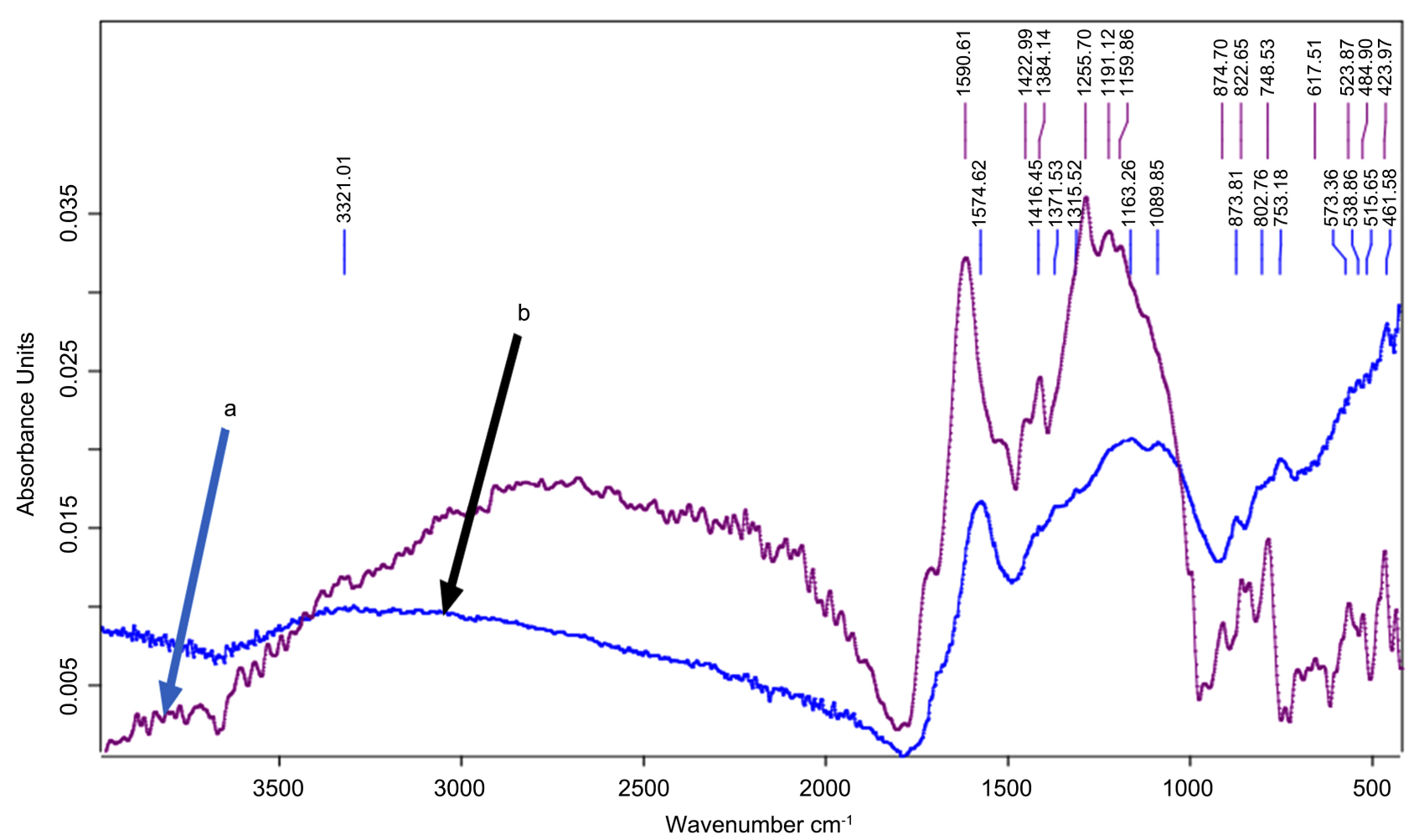

Figure 9. Infrared spectrum of ACK before adsorption (a) and after adsorption (b). 


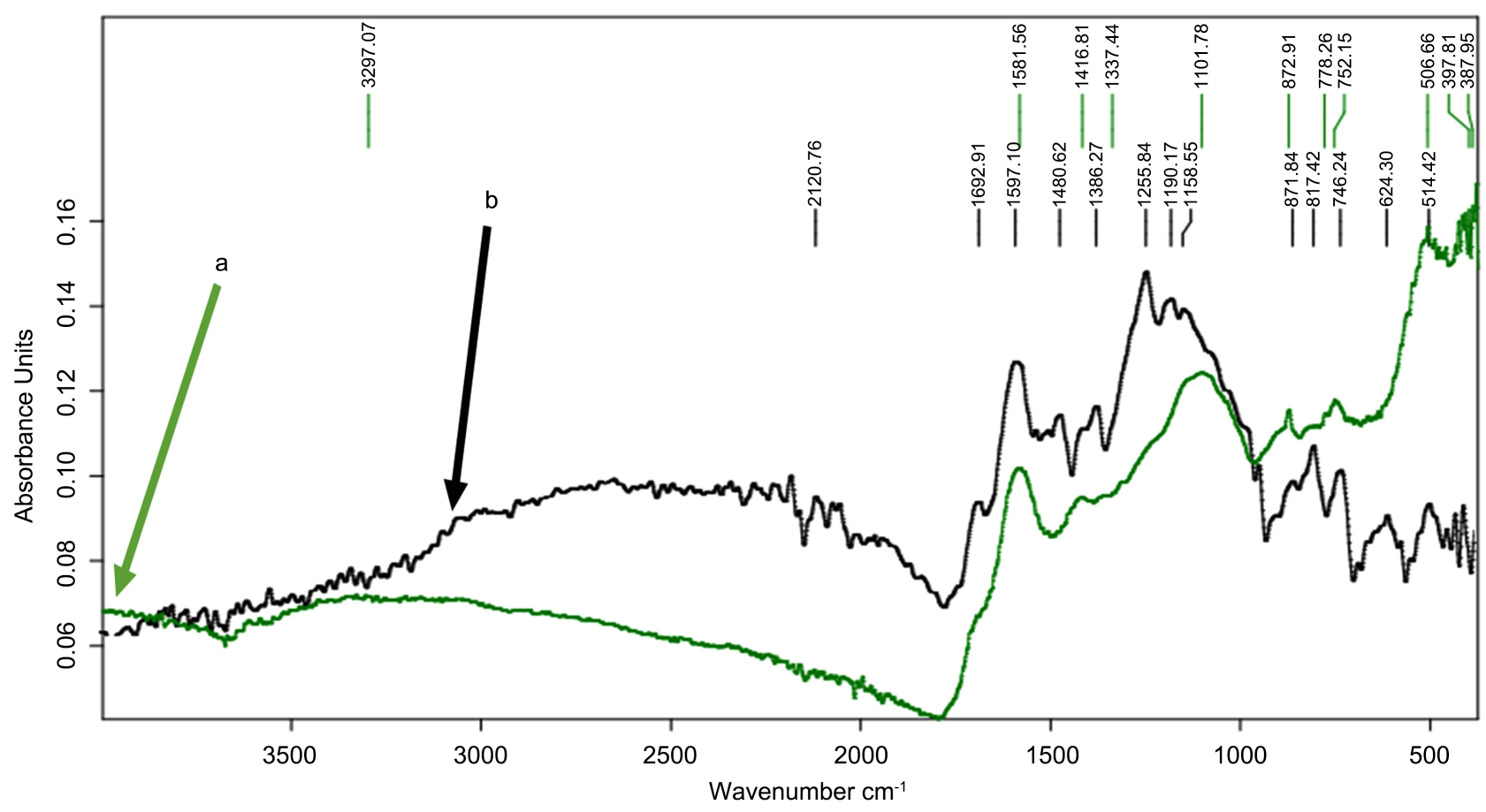

Figure 10. Infrared spectrum of ACP before adsorption (a) and after adsorption (b).

\section{Langmuir isotherm}

$$
\frac{1}{Q_{e}}=\frac{1}{Q_{m} K C_{e}}+\frac{1}{Q_{m}}
$$

\section{Freundlich isotherm}

$$
\ln Q_{e}=\ln K_{F}+(1 / n) \ln C_{e}
$$

\section{Dubinin-Kaganer-Radushkevich isotherm model}

$$
\ln Q_{e}=\ln Q_{m}-\beta \varepsilon^{2}
$$

where: $Q_{e}$ is the amount adsorbed at equilibrium $(\mathrm{mg} / \mathrm{g}), K_{F}$ is the Freundlich constant, $1 / \mathrm{n}$ is the heterogeneity factor which is related to the capacity and intensity of the adsorption, $C_{e}$ is the equilibrium concentration $(\mathrm{mg} / \mathrm{L}) \cdot \varepsilon=\mathrm{RTln}$ $\left(1+1 / C_{e}\right)$ is the Dubinin-Kaganer-Radushkevich constant. $Q_{m}=$ theoretical isotherm saturation capacity ( $\mathrm{mg} / \mathrm{g}), \beta$ is the Dubinin-Kaganer-Radushkevich isotherm constant $(\mathrm{mol} / \mathrm{kJ})^{2}$.

The adsorption isotherms for ACK and ACP obtained under optimal conditions are shown in Figure 11.

The adsorption isotherm of Tartrazine on ACP is type IV, characteristic of a mesoporous adsorbent. The presence of two layers result from the formation of a monolayer followed by a multilayer between the adsorbate and the adsorbent surface [28]. Here, the interaction between the molecules and the surface of the adsorbent are higher than those of the molecules themselves; the adsorption sites of the second layer will begin to be occupied when the first layer is fully saturated. The adsorption isotherm of tartrazine on ACK is also similar but the layers is less pronounced. The constants obtained from the isotherms models are given in Table 2. 


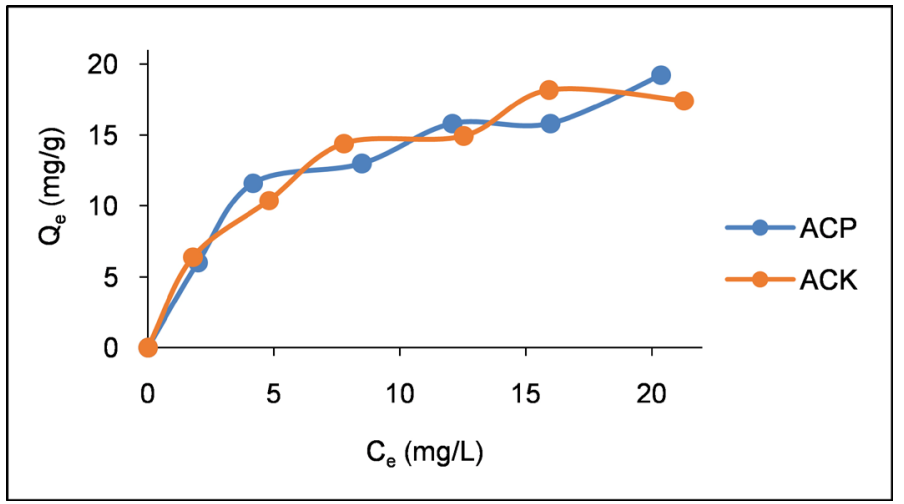

Figure 11. Quantities adsorbed based on the equilibrium concentrations.

Table 2. Langmuir, Freundlich, Dubinin-Kaganer-Radushkevich and Tempkin constants.

\begin{tabular}{|c|c|c|c|}
\hline Isotherm & Constants & $\mathrm{ACP}$ & ACK \\
\hline \multirow{4}{*}{ Langmuir } & $R^{2}$ & 0.9805 & 0.9824 \\
\hline & $Q_{m}\left(\mathrm{mg} \cdot \mathrm{g}^{-1}\right)$ & 24.57 & 21.598 \\
\hline & $K_{L}\left(\mathrm{~L} \cdot \mathrm{mg}^{-1}\right)$ & 0,165 & 0.222 \\
\hline & $R_{L}$ & 0.183 & 0.143 \\
\hline \multirow{3}{*}{ Freundlich } & $R^{2}$ & 0.9408 & 0.9531 \\
\hline & $K_{F}\left(\mathrm{mg} \cdot \mathrm{g}^{-1}\right)(\mathrm{L} / \mathrm{mg})^{-1 / \mathrm{n}}$ & 4.912 & 5.289 \\
\hline & $1 / \mathrm{n}$ & 0.468 & 0.425 \\
\hline \multirow{4}{*}{ DKR } & $R^{2}$ & 0.9221 & 0.8709 \\
\hline & $\beta\left(\mathrm{mol}^{2} \cdot \mathrm{J}^{-2}\right)$ & 0.549 & 3.973 \\
\hline & $Q_{m}\left(\mathrm{mg} \cdot \mathrm{g}^{-1}\right)$ & 16.815 & 15.863 \\
\hline & $E\left(\mathrm{~kJ} \cdot \mathrm{mol}^{-1}\right)$ & 0.954 & 0.355 \\
\hline \multirow{3}{*}{ Tempkin } & $R^{2}$ & 0.970 & 0.954 \\
\hline & $K_{T}\left(\mathrm{~L} \cdot \mathrm{mg}^{-1}\right)$ & 1.623 & 2.079 \\
\hline & $b_{T}\left(\mathrm{~kJ} \cdot \mathrm{mol}^{-1}\right)$ & 0.456 & 0.513 \\
\hline
\end{tabular}

The Langmuir model showed good correlation of experimental data indication adsorption is specific (chemisorption) for both adsorbents [1]. This suggest that adsorption takes place at uniform energy sites on the adsorbents surface. This is in good agreement with the results from infrared after adsorption, which shows the formation of a chemical bond between tartrazine molecules and the surface active sites of both adsorbents. The $R_{L}$ values of the Langmuir model is between 0 and 1 for both absorbents, hence adsorption is favourable [21]. The Freundlich correlation coefficients values near unity indicates that the equilibrium data is also consistent with this model, to an extent. Thus, a $1 / \mathrm{n}$ value be- 
tween zero and one shows that the surface of both adsorbents are heterogeneous [22]. This heterogeneity could be attributed to the different functional groups present on the adsorbent surface and to the existence of different pore sizes.

The Dubinin-Kaganer-Radushkevich isotherm adsorption energies are less than $8 \mathrm{~kJ} / \mathrm{mol}$ for both materials and indicate a physisorption mechanism attributed to the multilayer formation [16], which is in good agreement with type IV isotherm. If this value were greater than $8 \mathrm{~kJ} / \mathrm{mol}$ chemical adsorption or ion exchange could occur. However, given that the difference between the theoretical and experimental value of quantity adsorbed is large, this model does not accurately describe the adsorption of tartrazine ions on both materials. The value of the $b_{\mathrm{T}}$ constant of the Tempkin model is also less than $8 \mathrm{~kJ} / \mathrm{mol}$ indicating that the adsorbent-adsorbate interactions are weak and are characteristic of physisorption in agreement with type IV isotherm [29]. However, the positive value of this constant suggests a gravitational adsorption on the both materials [26].

\subsection{Study of Kinetic Models}

Adsorption is a time-dependent process, and determining the rate of adsorption is highly significant in the design and evaluation of an adsorbent in removing pollutants from wastewater [29]. The linear equations of the following kinetic models were used to study the adsorption reaction mechanism:

Pseudo-First order kinetic Model:

$$
\ln C_{t}=C_{0}-K_{1} t
$$

Pseudo-second order kinetic model:

$$
\frac{t}{Q_{t}}=\frac{1}{K_{2} Q_{e}^{2}}+\frac{t}{Q_{e}}
$$

Intra-particle diffusion model:

$$
Q_{t}=K_{i d} t^{0.5}+C
$$

Elovich model:

$$
\frac{\mathrm{d} Q}{\mathrm{~d} t}=\alpha \mathrm{e}^{-\beta q_{t}}
$$

Linearizing equation (9) using the $\alpha \beta \gg t, Q_{t}=0$ to $t=0, Q_{t}=Q_{t}$ at $t=t$, gives:

$$
Q_{t}=\ln (\alpha \beta)+\ln t
$$

where $Q_{e}$ and $Q_{t}$ are the sorption capacity $(\mathrm{mg} / \mathrm{g})$ at equilibrium and at time $t$ respectively. $K_{1}$ is the rate constant of pseudo-first order equation $\left(\mathrm{min}^{-1}\right), K_{2}$ is the pseudo-second order rate constant $\left(\mathrm{g} \cdot \mathrm{mg}^{-1} \cdot \mathrm{min}^{-1}\right), K_{i d}$ is the intra-particle diffusion constant $\left(\mathrm{mg} \cdot \mathrm{g}^{-1} \cdot \mathrm{min}^{-1}\right), \mathrm{C}$ is a constant, which relates an idea about the boundary layer thickness of the boundary. Table 3 below provides a comparison of the different kinetic models. 
Table 3. Constants and speed correlation coefficients of kinetic models.

\begin{tabular}{cccc}
\hline Kinetic Model & Constants & ACP & ACK \\
\hline Pseudo-first order & $R^{2}$ & 0.182 & 0.165 \\
& $K_{1}\left(\mathrm{~min}^{-1}\right)$ & -0.015 & -0.014 \\
$C_{0}\left(\mathrm{mg} \cdot \mathrm{L}^{-1}\right)$ & 7.326 & 7.472 \\
\hline Pseudo-second order & $\boldsymbol{R}^{2}$ & 0.995 & 0.999 \\
& $K_{2}\left(\mathrm{~g} \cdot \mathrm{min}^{-1} \cdot \mathrm{mg}^{-1}\right)$ & 0.605 & 0.076 \\
& $Q_{e}\left(\mathrm{mg}^{-1}\right)$ & 19.157 & 19.802 \\
& $h\left(\mathrm{mg} \cdot \mathrm{g}^{-1} \cdot \mathrm{min}^{-1}\right)$ & 222.222 & 30.03 \\
\hline Intra-particle diffusion & $R^{2}$ & 0.007 & 0.491 \\
& $K_{i d}\left(\mathrm{mg}^{2} \mathrm{~g}^{-1} \cdot \mathrm{min}^{-1}\right)$ & 46.500 & 41.760 \\
& $C$ & 0.003 & 0.031 \\
\hline
\end{tabular}

From the above table, only the pseudo-second-order model has a correlation coefficient ( $R^{2}$ value) close to unity for both adsorbents. This indicates that the chemisorption is the rate-limiting step, the same results have been obtained by [27]. Furthermore, the theoretical and experimental adsorbed quantities are close enough and confirm the assertion that was has been made in interpreting the FT-IR spectra after adsorption. The adsorption rate constant for ACK is smaller than for ACP. This could be partly due to faster fixation ( $t=5 \mathrm{~min}$ ) of tartrate ion on ACP than on ACK $(t=10 \mathrm{~min})$ [30]. This could attribute to the fact that ACP possesses higher surface area than ACK which lead to the more available surface active sites at the start of the process. This is also confirmed by the value of initial adsorption rate $(\boldsymbol{h})$ which shows that the flow of the tartrazine molecules is initially greater for ACP than ACK. Indeed the value of this parameter is seven times higher for ACP than that of ACK.

\subsection{Thermodynamic Study and Effect of Temperature}

To study the thermodynamic of the adsorption of tartrazine onto ACP and ACK, we carried experimental adsorption runs in which we varied the temperature of the adsorption milieu between the range of $30^{\circ} \mathrm{C}$ to $55^{\circ} \mathrm{C}$. The thermodynamic parameters studied are enthalpy $\left(\Delta H^{\circ}\right)$, entropy $\left(\Delta S^{\circ}\right)$ and Gibbs free energy $\left(\Delta G^{\circ}\right)$. The thermodynamic parameters were calculated from the following expressions [31]:

$$
\begin{gathered}
K_{d}=\frac{C_{a}}{C_{e}} \\
\Delta G=-R T \ln K_{d} \\
\ln K_{d}=\frac{\Delta S}{R}-\frac{\Delta H}{R T}
\end{gathered}
$$


where, $K_{d}$ is equilibrium constant, $C_{a}$ the concentration of adsorbate in equilibrium on the adsorbent $(\mathrm{mg} / \mathrm{L}), C_{e}$ the concentration of adsorbate in equilibrium in the solution $(\mathrm{mg} / \mathrm{L}), R$ the ideal gas constant $(8.314 \mathrm{~J} / \mathrm{K} / \mathrm{mol}), \Delta G^{\circ}$ $(\mathrm{kJ} / \mathrm{mol}), \Delta H^{\circ}(\mathrm{kJ} / \mathrm{mol}), \Delta S^{\circ}(\mathrm{kJ} / \mathrm{mol})$ are the change in free energy, enthalpy and entropy respectively.

By plotting a graph of $\ln K_{d}$ versus $1 / \mathrm{T}$ (Figure 12 and Figure 13), the values of $\Delta H^{\circ}$ and $\Delta S^{\circ}$ can be estimated from correlation coefficient value of ACK and $\mathrm{ACP}$ are respectively $\left(R^{2}=0.8736\right)$ and $\left(R^{2}=0.9111\right)$ indicating good linearity.

Table 4 shows that the Gibbs energy $\left(\Delta G^{\circ}\right)$ and the enthalpy $\left(\Delta H^{\circ}\right)$ are positive. This indicates that the adsorption is exothermic and spontaneous for ACP, requiring no energy input. By contrast, the reaction is exothermic but non-spontaneous for ACK, hence it requires energy input to start the process. In addition, the negative value of $\Delta S$ in both cases shows that the adsorption progresses with increasing disorder in the solid solution interface. We also note that the value of $\Delta S^{\circ}$ for ACP is near to zero and shows that there is more disorder during adsorption of the latter, which is in agreement with the constant

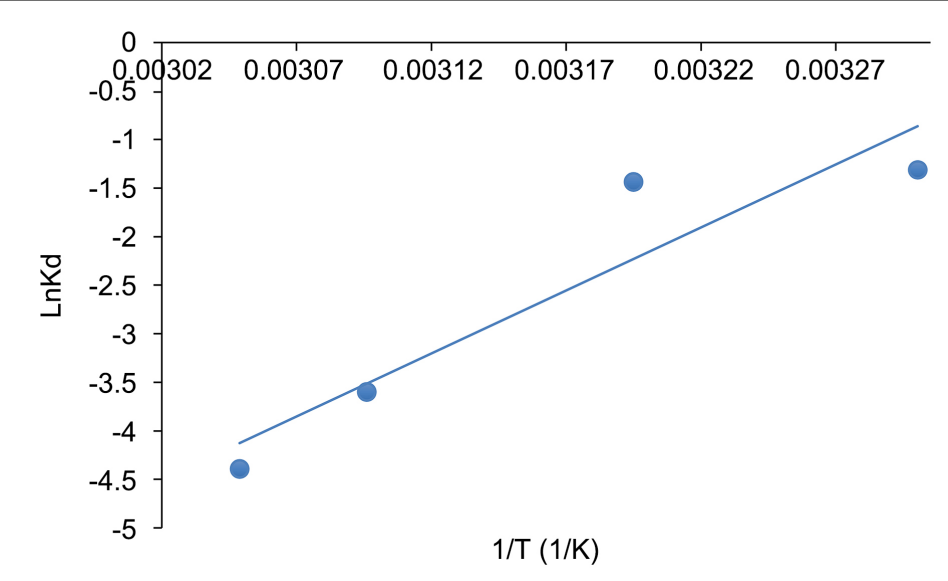

Figure 12. Plot of $\ln K_{d}$ versus $1 / T$ for adsorption of tartrazine on ACK.

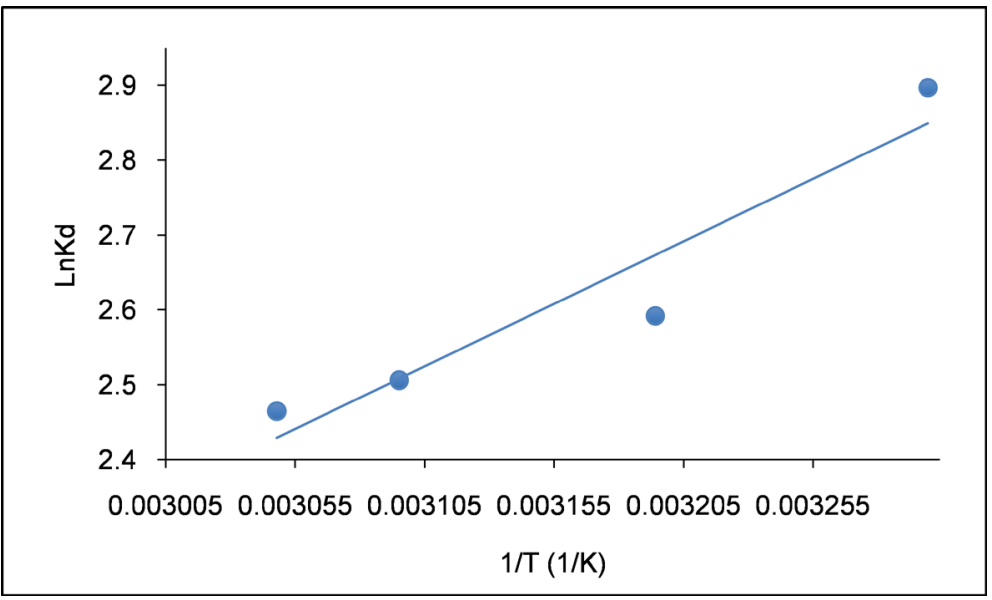

Figure 13. Plot of $\ln K_{d}$ versus $1 / T$ for adsorption of tartrazine on ACP. 
Table 4. Thermodynamic parameters for adsorption of tartrazine by ACP and ACK.

\begin{tabular}{ccccc}
\hline Adsorbent & $\mathrm{T}(\mathrm{K})$ & $\Delta \mathrm{G}^{\circ}(\mathrm{kJ} / \mathrm{mol})$ & $\Delta \mathrm{H}^{\circ}(\mathrm{kJ} / \mathrm{mol})$ & $\Delta \mathrm{S}^{\circ}(\mathrm{J} / \mathrm{mol} \cdot \mathrm{K})$ \\
\hline 303 & -7.297 & & \\
ACP & 313 & -6.745 & -13.871 & -22.090 \\
& 323 & -6.729 & & \\
& 328 & -6.723 & & -363.064 \\
ACK & 303 & 3.298 & & \\
& 313 & 3.733 & & \\
& 323 & 9.658 & & \\
\hline
\end{tabular}

initial velocity model of pseudo-second order (seven times greater than that of ACK), showing a strong affinity between the ACP and tartrazinemolecules. Moreover, examination of values of standard enthalpy of adsorption $(<40 \mathrm{~kJ} / \mathrm{mol})$ [32] indicated the presence of physical attractive process make by Van Der Waals interaction during the multilayers formation. Therefore, it is reasonable to conclude that both physical adsorption and chemical adsorption equally participate in the overall process of tartrazine adsorption on ACK and ACP materials.

\section{Conclusion}

Two adsorbents ACP and ACK were prepared and characterized. They were successfully applied to elimination of tartrazine in aqueous solution. Several factors affecting adsorption such as contact time, adsorbent dose, initial concentration of adsorbate and temperature were also studied. The variation of $\mathrm{pH}$ and initial concentration gave an optimum $\mathrm{pH}$ of 2 ; the quantity adsorbed increased with increasing initial concentration. We also found that the degree of heterogeneity affected the quantity adsorbed. Kinetic studies showed that chemisorption was the rate-limiting step; however, equilibrium studies revealed the presence of physical adsorption process. Additionally, thermodynamic study revealed that the adsorption was exothermic for both adsorbents, but it was spontaneous for ACP and not for ACK. The results obtained in this work confirm that $\mathrm{AC}$ obtained from Cola nutshells could be used for the removal of tartrazine from wastewater.

\section{Acknowledgements}

The authors of this work sincerely wish to thank the members of the Adsorption and Surface "Research Unit" of the Applied Physical and Analytical Chemistry Laboratory of the University of Yaoundé I.

\section{Conflicts of Interest}

The authors declare no conflicts of interest regarding the publication of this paper. 


\section{References}

[1] Li, K., Zheng, Z., Huang, X., Zhao, G., Feng, J. and Zhang, J. (2009) Equilibrium, Kinetic and Thermodynamic Studies on the Adsorption of 2-Nitroaniline onto Activated Carbon Prepared from Cotton Stalk Fibre. Journal of Hazardous Materials, 166, 213-220. https://doi.org/10.1016/j.jhazmat.2008.11.007

[2] Tsai, W.T., Chang, C.Y., Ing, C.H. and Chang, C.F. (2004) Adsorption of Acid Dyes from Aqueous Solution on Activated Bleaching Earth. Journal of Colloid and Interface Science, 275, 72-78. https://doi.org/10.1016/j.jcis.2004.01.072

[3] Zein, R., Ningsih, Z.S., Novita, L., Swesty, N., Mukhlis and Novrian, H. (2016) Treatment of Waste Water Noodle Industry with a Multi-Soil-Layering (MSL) System. Research Journal of Pharmaceutical Biological and Chemical Sciences, 7, 88-94.

[4] Giger, A. (2002) Chemical Synthesis Project. A New Yellow Carotenoid. Pure and Applied Chemistry, 74, 1383-1390. https://doi.org/10.1351/pac200274081383

[5] Gupta, V.K., Jain, R., Nayak, A., Agarwal, S. and Shrivastava, M. (2011) Removal of the Hazardous Dye-Tartrazine by Photodegradation on Titanium Dioxide Surface. Materials Science and Engineering. C, 31, 1062-1067. https://doi.org/10.1016/j.msec.2011.03.006

[6] Wang, L., Zhang, J. and Wang, A. (2011) Fast Removal of Methylene Blue from Aqueous Solution by Adsorption onto Chitosan-g-Poly (Acrylic Acid)/Attapulgite Composite. Desalination, 266, 33-39. https://doi.org/10.1016/j.desal.2010.07.065

[7] Abdullah, A.L., Salleh, M.M., Mazlina, M.S., Noor, M.J.M.M., Osman, M.R., Wagiran, R. and Sobri, S. (2005) Azo Dye Removal by Adsorption Using Waste Biomass: Sugarcane Bagasse. International Journal of Engineering and Technology, 2, 8-13.

[8] Tanaka, T., Takahashi, O., Oishi, S. and Ogata, A. (2008) Effects of Tartrazine on Exploratory Behavior in a Three-Generation Toxicity Study in Mice. Reproductive Toxicology, 26, 156-163. https://doi.org/10.1016/j.reprotox.2008.07.001

[9] Stevenson, D.D., Simon, R.A., Lumry, W.R. and Mathison, D.A. (1986) Adverse Reactions to Tartrazine. Journal of Allergy and Clinical Immunology, 78, 182-191. https://doi.org/10.1016/0091-6749(86)90011-4

[10] Borzelleca, J.F. and Hallagan, J.B. (1988) Chronic Toxicity/Carcinogenicity Studies of FD \& C Yellow No. 5 (Tartrazine) in Rats. Food and Chemical Toxicology, 26, 179-187. https://doi.org/10.1016/0278-6915(88)90117-2

[11] Nsami, J.N. and Mbadcam, J.K. (2013) The Adsorption Efficiency of Chemically Prepared Activated Carbon from Cola Nut Shells by $\mathrm{ZnCl}_{2}$ on Methylene Blue. Journal of Chemistry, 2013, Article ID: 469170. https://doi.org/10.1155/2013/469170

[12] Mbadcam, J.K., Ngomo, H.M., Tcheka, C., Rahman, A.N., Djoyo, H.S. and Kouotou, D. (2009) Batch Equilibrium Adsorption of Cyanides from Aqueous Solution onto Copper- and Nickel-Impregnated Powder Activated Carbon and Clay. Journal of Environmental Protection, 3, 53-57.

[13] Ketcha, J.M., Dina, D.J.D., Ngomo, H.M. and Ndi, N.J. (2012) Preparation and Characterization of Activated Carbons Obtained from Maize Cobs by Zinc Chloride Activation. Chemical Science International Journal, 2, 136-160. https://doi.org/10.9734/ACSJ/2012/1806

[14] Wu, F.C., Tseng, R.L. and Juang, R.S. (2005) Preparation of Highly Microporous Carbons from Fir Wood by KOH Activation for Adsorption of Dyes and Phenols from Water. Separation and Purification Technology, 47, 10-19.

https://doi.org/10.1016/j.seppur.2005.03.013 
[15] Kundu, S., Chowdhury, I.H. and Naskar, M.K. (2018) Hierarchical Porous Carbon Nanospheres for Efficient Removal of Toxic Organic Water Contaminants of Phenol and Methylene Blue. Journal of Chemical \& Engineering Data, 63, 559-573. https://doi.org/10.1021/acs.jced.7b00745

[16] Kobya, M., Demirbas, E., Senturk, E. and Ince, M. (2005) Adsorption of Heavy Metal Ions from Aqueous Solutions by Activated Carbon Prepared from Apricot Stone. Bioresource Technology, 96, 1518-1521. https://doi.org/10.1016/j.biortech.2004.12.005

[17] Jaguaribe, E.F., Medeiros, L.D.L., Barreto, M.D.C.S. and Araujo, L.P.D. (2005) The Performance of Activated Carbons from Sugarcane Bagasse, Babassu, and Coconut Shells in Removing Residual Chlorine. Brazilian Journal of Chemical Engineering, 22, 41-47. https://doi.org/10.1590/S0104-66322005000100005

[18] Guler, C., Copur, Y. and Tascioglu, C. (2008) The Manufacture of Particleboards Using Mixture of Peanut Hull (Arachis hypogaea L.) and European Black Pine (Pinus nigra Arnold) Wood Chips. Bioresource Technology, 99, 2893-2897. https://doi.org/10.1016/j.biortech.2007.06.013

[19] Hameed, B.H., Din, A.M. and Ahmad, A.L. (2007) Adsorption of Methylene Blue onto Bamboo-Based Activated Carbon: Kinetics and Equilibrium Studies. Journal of Hazardous Materials, 141, 819-825. https://doi.org/10.1016/j.jhazmat.2006.07.049

[20] Demiral, H., Demiral, I., Tümsek, F. and Karabacakoğlu, B. (2008) Adsorption of Chromium(VI) from Aqueous Solution by Activated Carbon Derived from Olive Bagasse and Applicability of Different Adsorption Models. Chemical Engineering Journal, 144, 188-196. https://doi.org/10.1016/j.cej.2008.01.020

[21] Yahaya, N.K.E.M., Abustan, I., Latiff, M.F.P.M., Bello, O.S. and Ahmad, M.A. (2011) Fixed-Bed Column Study for Cu(II) Removal from Aqueous Solutions Using Rice Husk Based Activated Carbon. International Journal of Engineering and Technology, 11, 248-252.

[22] Nouri, H. and Ouederni, A. (2013) Experimental and Modeling Study of Sulfur Dioxide Oxidation in Packed-Bed Tubular Reactor. International Journal of Innovation and Applied Studies, 3, 1045-1052.

[23] Ndi, N.J., Anagho, G.S., Ghogomu, J.N. and Belibi, E.P. (2014) Physical and Chemical Characteristics of Activated Carbon Prepared by Pyrolysis of Chemically Treated Cola Nut (Cola acuminata) Shells Wastes and Its Ability to Adsorb Organics. International Journal of Advanced Chemical Technology, 3, 1-13.

[24] El Nemr, A., Khaled, A., Abdelwahab, O. and El-Sikaily, A. (2008) Treatment of Wastewater Containing Toxic Chromium Using New Activated Carbon Developed from Date Palm Seed. Journal of Hazardous Materials, 152, 263-275. https://doi.org/10.1016/j.jhazmat.2007.06.091

[25] Banerjee, S. and Chattopadhyaya, M.C. (2017) Adsorption Characteristics for the Removal of a Toxic Dye, Tartrazine from Aqueous Solutions by a Low Cost Agricultural By-Product. Arabian Journal of Chemistry, 10, S1629-S1638. https://doi.org/10.1016/j.arabjc.2013.06.005

[26] Abega, A.V., Nsami, N.J. and Manga, N.H. (2015) The Performance of Activated Carbon Based Cola Nuts Shells for the Removal of $\mathrm{Co}(\mathrm{II})$ and $\mathrm{Ni}$ (II) Ions from Aqueous Solution. International Journal of Innovative Science, Engineering \& Technology, 2, 676-683.

[27] Srivastava, V.C., Mall, I.D. and Mishra, I.M. (2008) Adsorption of Toxic Metal Ions onto Activated Carbon: Study of Sorption Behaviour through Characterization and Kinetics. Chemical Engineering and Processing. Process Intensification, 47, 1269-1280. 
https://doi.org/10.1016/j.cep.2007.04.006

[28] Ngouateu, R.B., Kouotou, D. and Belibi, P.D. (2015) Kinetics and Equilibrium Studies of the Adsorption of Phenol and Methylene Blue onto Cola Nut Shell Based Activated Carbon. International Journal of Current Research and Review, 7, 1.

[29] Jiang, L., Liu, T., He, H., Pham-Huy, L.A., Li, L., Pham-Huy, C. and Xiao, D. (2012) Adsorption Behavior of Pazufloxacinmesilate on Amino-Functionalized Carbon Nanotubes. Journal of Nanoscience and Nanotechnology, 12, 7271-7279. https://doi.org/10.1166/jnn.2012.6562

[30] Bhattacharyya, K.G. and Sen Gupta, S. (2006) Adsorption of Chromium(VI) from Water by Clays. Industrial \& Engineering Chemistry Research, 45, 7232-7240. https://doi.org/10.1021/ie060586j

[31] Saha, P. and Chowdhury, S. (2011) Insight into Adsorption Thermodynamics. In: Tadashi, M., Ed., Thermodynamics, InTech, London, 349-364. https://doi.org/10.5772/13474

[32] Gouamid, M., Ouahrani, M.R. and Bensaci, M.B. (2013) Adsorption Equilibrium, Kinetics and Thermodynamics of Methylene Blue from Aqueous Solutions Using Date Palm Leaves. Energy Procedia, 36, 898-907.

https://doi.org/10.1016/j.egypro.2013.07.103 